\title{
Editor's Introduction to Volume 40, Issue 1
}

\section{Anne EC McCants}

With this issue, Social Science History begins its fortieth year of publication. The journal is also in its second year of publication with Cambridge University Press. So this seems an especially propitious moment to take stock of who we are and how we conceive of our mission, to both our parent organization and to the wider world of interdisciplinary scholarly inquiry. Since our founding in 1976, the journal remains firmly rooted in the organizational and intellectual apparatus of the Social Science History Association (SSHA). We embrace the cross-disciplinary and grassroots "network" structure of the annual meetings in forming our Editorial Board, with its rotating membership and diverse representation from across the historical and social science disciplines. We actively seek out new scholarship, as well as encourage SSHA members to propose special issues that address a common theme or scholarly question from multiple disciplinary points of view and address different places and time periods. But we also remain fundamentally historical in our purview, dedicated to "improv[ing] the quality of historical explanation in every manner possible, but particularly by encouraging the selective use and adaptation in historical ... research of relevant theories and methods from related disciplines, particularly the social sciences."1

History is, in the most rudimentary sense, the accumulated information about that which has come before us. Social science history, though, is more accurately described as the study of how human institutions and practices change over time, with a search for the forces that act upon them or in turn create such change. The temporal element to which we are committed is a dynamic one. It is not the purview of Social Science History to simply make note of past change, but instead to promote the critical analysis of temporal trajectories within institutions and practices and the dynamic forces that act upon them. Social science history is thus a scholarly pursuit characterized by both a temporal context and by a methodological commitment to understand the social forces that effect change, and change inherently, over time.

Everything has a past, so the study of history is of necessity an enterprise with a broad ambit. It must not only attend to culture, economy, society, and polity, and to science, art, music, literature, faith, and ideas of all kinds, but also to environment, human migration, technology, trade, diplomacy, war, and so forth. But whatever its topical focus, history has as its primary task to strip away the obscuring layers of nostalgia, myth, and forgetfulness - intentional or otherwise - that accrete over time. The thoughtful historian is often faced with raw material consisting of competing, indeed contradictory, accounts of people, events, or processes. Social Science History is committed to the multiple angles of methodological perspective that help us see beyond half-truths and more fully appreciate the true richness of human experience.

1. Taken from Part 1 of "Constitution of the Social Science History Association." Social Science History 1 (1) (1976): iii. 
Interdisciplinary thinking can also open up a fuller understanding of the complex problems that confront us every day, problems often deeply situated in an historical context perhaps too little appreciated. In some cases, interdisciplinary thinking facilitates change in the scale at which we view a problem, allowing us to see patterns that are not easily visible in the original view. In other cases, it can make transparent the assumptions on which many a disciplinary understanding are predicated, or the presumed invariability within standard analyses. In yet other instances, the adoption of a social scientific methodology can make explicit hypotheses that would otherwise remain implicit and thus untested. In a world flush with data, and no prospect for data production to slow anytime soon, the analytic tools, both qualitative and quantitative, of the social science historian are as critical now as they have ever been.

So our core mission as the flagship journal of the SSHA remains. Our insistence that our authors demonstrate both a clear temporal frame for their work as well as a rigorous analytical mode of inquiry continues. What has changed over the last 40 years is the scope and reach of our enterprise. The SSHA is more international than it has ever been both in its membership and in the topics that populate the programs of its annual meetings. The Editorial Board of Social Science History is likewise increasingly committed to as broad a comprehension of the social world as possible, including the communities, geographic regions, and time periods for which data is less forthcoming, and traditional historical study has been more limited. With the high international visibility of our new publisher, Cambridge University Press, it is our hope to enter the next decade with not only a renewed sense of purpose, but also a vision to expand historical empathy, critical knowledge acquisition, analytical rigor, and the cultivation of wisdom to the multifaceted problems that confront our diverse but intimately connected global world. 